\title{
A civilização das imagens - Entrevista com Jacques Aumont
}

The Civilization of the images - Interview with Jacques Aumont

Lisandro Nogueira

Professor no Curso de Comunicação Social da UFG/G0/BR. lisandronogueira@gmail.com

Tradução de Luis Araujo

\section{RESUMO}

Nesta entrevista exclusiva, concedida ao professor Lisandro Nogueira, o teórico francês Jacques Aumont fala da atualidade da Civilização das Imagens, elogia o melodrama canônico, comenta seu livro mais estudado no Brasil, "A imagem" (outra versão atualizada será publicada ainda neste ano na França), relativiza o conceito de Sociedade do espetáculo, de Guy Debord e comenta a importância do cinema moderno e de Glauber Rocha.

PALAVRAS-Chave: Jacques Aumont; civilização das imagens; melodrama

\section{ABSTRACT}

In this exclusive interview, granted to Professor Lisandro Nogueira, the French film theorist Jacques Aumont speaks of today's civilization of Images, praises the canonical melodrama, discusses his most studied book in Brazil, "The Image" (another updated version will be published later this year in France), puts into perspective Guy Debord's concept of Society of the Spectacle, and comments on the importance of modern cinema and Glauber Rocha.

KeYwords: Jacques Aumont; civilization images; melodrama 
pesquisador e crítico Jacques Aumont foi professor na Université de Paris III - Sorbonne Nouvelle e é autor de vários livros sobre cinema. No Brasil foram traduzidos "A imagem", "A teoria dos cineastas", "A estética do filme", "O cinema e a encenação", "A análise do filme", "O olho interminável" e "Dicionário teórico e crítico de cinema".

- Lisandro Nogueira - "A civilização das imagens: o que resta do cinema?" é tema de uma conferência do senhor. Isso quer dizer que não temos mais o cinema do modo como ele foi formulado ao longo do século 20? Pode ser considerado um modelo estético ultrapassado? Mas como explicar a permanência do melodrama como um gênero forte no cinema?

Jacques Aumont - Eu respondo a esta mesma pergunta em pleno festival de Cannes e, evidentemente, o cinema, como indústria, comércio e prática social, se mantém muito bem. Cada ano traz a sua cota de filmes e há alguns que são mesmo muito interessantes. Na minha idade, pode-se começar a pensar que não há muitas propostas de filmes bastante originais - e que, entre todos os filmes exibidos em Cannes este ano, os mais surpreendentes sejam talvez o de Jean-Luc Godard, um octogenário, e o de Manoel de Oliveira, um homem centenário. Mas isso não impede que o cinema continue a sua trajetória, conforme as mesmas fórmulas do século 20 - tudo pelo simples fato de que essas fórmulas são muito antigas, bem anteriores ao cinema, que não inventou grandes coisas no plano narrativo (nem mesmo o flashback, que é de origem literária). Quanto aos "modelos estéticos", eu não tenho muito a dizer. Após um século de filmes, é claro que existem vários modelos; o cinema clássico não se equivale ao cinema moderno, há vários momentos bem-sucedidos da vanguarda (incluindo as realizações do Brasil), mas, globalmente, o cinema não conheceu uma revolução igual àquela que foi, na pintura, a invenção da abstração. Hoje, como há cem anos, contam-se histórias mais ou menos verossímeis, mais ou menos fantásticas - sempre com a intenção de seduzir o destinatário, o que significa também que se respeita mais ou menos as velhas receitas dramáticas do pai Aristóteles. A bem dizer, o melodrama não me parece exatamente um gênero, mas um tipo de narrativa que é fundado em torno da peripécia e que pode ser encontrado de um jeito ou de outro em todos os gêneros. $\mathrm{O}$ melodrama sempre existiu, e o cinema que nós chamamos de "clássico" não é outra coisa - até mesmo nas obras dos grandes diretores - do que uma coleção de melodramas. O que é novo hoje em dia é o sentimento de sua proliferação, mas isso diz respeito, a bem dizer, mais à televisão do 
que ao cinema. Eu me permitiria observar aqui que um país como o seu, onde a principal rede de televisão transmite quatro telenovelas por dia e onde essas difusões têm recordes de audiência, pode-se certamente ter o sentimento de que o melodrama é o modo dominante de narrativas cinematográficas. Isso talvez seja menos evidente em outros países, onde a relação cinema/ televisão/fluxo de internet é distribuída de forma diferente (na Europa, a televisão perdeu muito de sua audiência e de sua influência, ela não é mais a principal mídia - é a internet que ocupa esse lugar atualmente). Além disso, apesar de todos os defeitos evidentes (seu otimismo arraigado, sua superficialidade e, sobretudo, o fato de que ele repousa sobre a identificação do espectador com modelos fabricados), o melodrama - especialmente o melodrama de massa tem virtudes educativas e políticas. Depois de dez ou quinze anos, muitos problemas sociais (as pessoas com necessidades especiais, as sexualidades, a crise do casamento, etc.) foram abordados bastante e com eficácia por esse viés. Diante disso, pode-se de fato reclamar do melodrama?

- LN - O seu livro A Imagem tornou-se um clássico entre professores e estudantes de cinema e audiovisual no Brasil. Quais os motivos para essa obra ser tão importante e rivalizar inclusive com as Letras?

JA - Não cabe a mim dizer se esse livro é "importante". Com efeito, sei que ele fez sucesso nos países onde foi traduzido, e por uma razão simples: trata-se de um panorama que dá acesso rapidamente a diversas questões diferentes e que procura não tirar partido muito claramente de uma aproximação teórica determinada. Dito isso, é um livro muito envelhecido. Escrito há vinte anos, ele não dá conta das grandes novidades destes dois últimos decênios: os dados numéricos, a internet, o desenvolvimento das obras com imagens em movimento na arte contemporânea etc. Ao contrário, certas aproximações que o livro apresenta são hoje totalmente ultrapassadas e de interesse reduzido (penso particularmente em tudo que se origina da Semiologia de inspiração linguística, da Psicanálise, da crítica ideológica de teor marxista). Por causa disso, preparei uma edição totalmente nova, que reequilibra as coisas e contempla, além das subversões sociológicas a respeito da imagem, as mudanças sofridas na paisagem teórica. É impossível hoje em dia ignorar, por exemplo, a Antropologia da Imagem de Hans Belting, os desenvolvimentos da filosofia do "figural", de Gilles Deleuze a Georges Didi-Huberman, o problema do médium e aquele da 
matéria da imagem etc. Essa nova edição (que será lançada no final deste ano de 2011) deverá assim, expressamente, dar conta também da dimensão histórica, lamentavelmente ausente na primeira edição.

- LN - Quando se fala na preponderância da imagem nos dias atuais, sempre é citado o livro de Guy Debord sobre a "sociedade do espetáculo": as imagens como um suporte desse espetáculo. O senhor concorda com as teses de Debord?

JA - Eu não estou totalmente convencido de que a imagem ocupe um lugar preponderante, como você afirma. A verdade é que, jamais na história da humanidade tantas imagens tornaramse facilmente tão acessíveis e os seres humanos nunca viram, como agora, tantas imagens em sua vida. Isso, aliás, representa um duplo corte: a avalanche de imagens tem como consequência, provavelmente, a redução de parte de sua força (sensacional e ideal); porém, de outro lado, os "consumidores" de imagens nunca estiveram tão bem informados sobre o que é uma imagem e também tão conscientes de seus poderes e limites. Ainda, o uso atual das imagens não me parece mais enganador ou perigoso do que foi nos séculos 19 e 20. No que se refere às teses de Guy Debord, parece-me que elas guardam um caráter profundamente histórico e datado. Certamente, pode-se ter a impressão de que a espetacularização é ainda amplificada por essa proliferação das imagens. No entanto, no que me concerne, sou mais sensível aos efeitos de conhecimento que os meios de difusão do saber, baseados na imagem, provocam, numa escala muito ampla e em todas as camadas da sociedade. Todas as pessoas hoje em dia conduzem uma parte da sua vida sob a forma de imagem (com o YouTube ou o Facebook) e elas têm clareza disso. O mundo político é apenas uma grande cena de teatro - e a maioria das pessoas tem consciência disso também (no fundo, é o triunfo de Debord, cujas teses tornaram-se quase evidentes [...])

- LN - Glauber Rocha é um dos principais cineastas do Brasil. No seu livro sobre os cineastas teóricos, o senhor faz referência à sua obra. Qual a importância dele para a "teoria dos cineastas"?

JA - É um pouco paradoxal apresentar Glauber Rocha como um teórico. Seu lugar na história do cinema deve-se evidentemente, antes de tudo, aos seus filmes, que são formidáveis. Glauber 
pertenceu a um movimento (o Cinema Novo) e a uma geração que tinha justamente vinte anos antes de 1968, e, tanto num caso como no outro, isso pode ser lido em sua obra. Entretanto, ele foi sobretudo um poeta - ou seja, uma personalidade inclassificável, que soube impor tanto as suas idiossincrasias quanto as suas invenções. Desse ponto de vista, ele é contemporâneo de Carmelo Bene (para quem ofereceu um pequeno papel em Claro), de Werner Schroeter e de Melvin Van Peebles, de Sweet Sweetback. Ao mesmo tempo, não há filmes mais políticos do que os seus - até o último, A Idade da Terra, que deveria certamente ser projetado em todos os festivais de filmes ecológicos. Se eu o coloquei entre os cineastas teóricos foi, paradoxalmente, porque ele não aceitaria ser rotulado dessa maneira, eu creio. Sua reflexão ideológica e política sobre o cinema é que é interessante, sendo suficientemente cavada para atingir uma verdadeira força teórica. O que é apaixonante em sua obra - e que eu a faço somente aflorar no meu livro - é a contradição motriz entre a recusa do estético pelo estético (aquilo que é denominado, de forma zombeteira, de eztetyk) e o desenvolvimento de um estilo extremamente pessoal e expressivo. Há ainda em sua obra a crença na possibilidade de exposição imediata de um fundamento político (a "estética da fome") pelo estilo - o que lhe permite aliás procurar modelos tanto em Eisenstein quanto em Rossellini, seu contrário - e isso, sem dúvida, continua sendo uma intuição muito provocante. 